\title{
Predictive value of PAPP-A for ectopic pregnancy and analysis of related factors
}

\author{
XIAOYUN ZHANG and CHUNXIA WANG \\ Department of Obstetrics, Affiliated Hospital of Jining Medical University, Jining, Shandong 272000, P.R. China
}

Received March 10, 2020; Accepted December 14, 2020

DOI: $10.3892 / \mathrm{etm} .2021 .10233$

\begin{abstract}
The present study was designed to analyze the expression of pregnancy-associated plasma protein-A (PAPP-A) in the serum of patients with ectopic pregnancy (EP) and related factors inducing this condition. Seventy-five patients with EP admitted to the Affiliated Hospital of Jining Medical University from January 2018 to February 2019 were selected as the research group, and another 59 healthy pregnant women of the corresponding age, gravidity and gestational week were enrolled in the control group. ELISA was employed to detect the serum expression levels of PAPP-A and inflammatory factors such as interleukin-8 (IL-8) and tumor necrosis factor- $\alpha$ (TNF- $\alpha$ ). ROC was adopted to evaluate the diagnostic value of serum PAPP-A in patients with EP, and Pearson correlation coefficient was applied to analyze the correlation of PAPP-A with inflammatory factors IL- 8 and TNF- $\alpha$. Serum PAPP-A expression was significantly lower in EP patients than those in the control group. The area under the curve (AUC) of serum PAPP-A in diagnosing EP patients was 0.812, and the PAPP-A value in the control group was significantly higher than that of the research group at 7-8 weeks and $\geq 9$ weeks. With regard to the expression of inflammatory factors, the research group presented markedly higher IL- 8 and TNF- $\alpha$ levels than the control group. PAPP-A was negatively related to inflammatory factors IL- 8 and TNF- $\alpha$ in the research group. In addition, it was revealed that patients with a history of genital surgery, salpingotomy, pelvic infection, EP or low PAPP-A expression were at high risk of EP. In conclusion, PAPP-A was revealed to be lowly expressed in the serum of EP patients, and to negatively be correlated with inflammatory factors IL-8 and TNF- $\alpha$, which may serve as a useful marker for the diagnosis and prognosis of EP.
\end{abstract}

Correspondence to: Dr Chunxia Wang, Department of Obstetrics, Affiliated Hospital of Jining Medical University, 79 Guhuai Road, Rencheng, Jining, Shandong 272000, P.R. China

E-mail: cuoia0@163.com

Key words: pregnancy-associated plasma protein-A, ectopic pregnancy, prognosis, diagnosis, risk factors

\section{Introduction}

Ectopic pregnancy (EP) is the main cause of maternal morbidity and mortality in the first trimester $(1,2)$. With the occurrence of embryo transfer and in vitro fertilization, the incidence of EP has increased sharply, leading to mass maternal and sporadic deaths $(3,4)$, which account for approximately $10 \%$ of all pregnancy-related deaths (5). Complications caused by EP remain a major cause of morbidity and mortality in early pregnancy (6). In addition, little is known about the treatment and predictive factors of this complication (7), and its early symptoms are not obvious, and easily confused with threatened abortion (8). Therefore, determining the development, occurrence, prognosis and potential mechanism of EP is conducive for clinicians to explore a more feasible treatment plan for this condition.

First found in the plasma of pregnant women, PAPP-A is a metalloproteinase that plays a key part in regulating the activity of insulin-like growth factors (9), and is subsequently acknowledged to be a multifunctional regulator in various pathological processes (10). In addition, it is a major physiological regulator of insulin-like growth factor binding protein-4 (IGFBP-4), which cleaves the IGFBP4/IGF1 complex to release insulin-like growth factor 1 (IGF-1), and then regulates its bioavailability (11). However, there are other studies indicating that the aberrant expression of PAPP-A disrupts the regulation of the availability of IGF-1 and thus affects the biology of tumors (12-14). Previous studies $(15,16)$ have demonstrated that, the prevention and prognosis of an adverse pregnancy is of great clinical significance from a medical point of view, and is particularly challenging for the scientific community, family and society, and that ultrasounds combined with PAPP-A can better diagnose and predict an abnormal pregnancy. However, the relationship between serum PAPP-A and the diagnosis, prognosis, related factors, as well as the possible molecular mechanism of EP remains poorly understood.

Therefore, by examining the expression of PAPP-A in EP, its clinical value in EP, the related factors inducing the disease and the possible molecular mechanism were explored, with the aim to identify reliable diagnostic and prognostic markers and potential drug targets for EP.

\section{Patients and methods}

General information. From January 2018 to February 2019, 75 patients with EP admitted to the Affiliated Hospital of 
Jining Medical University were included in the research group, and another 59 healthy pregnant women of the corresponding age, gravidity and gestational week were enrolled in the control group (17). Patients in the research group were 21-35 years old, with an average age of $25.73 \pm 7.23$ years, while those in the control group were 20-35 years old, with an average age of $26.64 \pm 7.35$ years.

Inclusion and exclusion criteria. The inclusion criteria were as follows: Aged 20-35 years and naturally conceived; patients diagnosed with EP laparoscopically (18); with complete clinical general data, amenorrhea between 27-88 days; and no history of fetus protection during pregnancy. Ultrasound examination confirmed that there was no pregnancy sac in the uterine cavity of the patient, and there were heterogeneous abnormal echogenic masses outside the uterine cavity revealing a trend of gradual increase, or there were fetal buds and fetal heart beats. All of the enrolled patients were informed of this study and signed the written informed consent. The experimental process was approved by the Medical Ethics Committee of the Affiliated Hospital of Jining Medical University and was in accordance with the 2013 version of the Declaration of Helsinki. The exclusion criteria were as follows: Patients with communication barriers or severe mental illness, those combined with malignant tumor or serious heart, lung, liver, kidney and other functional disorders, or those who were in urgent need of surgery for intraperitoneal hemorrhage with unstable vital signs were excluded.

Methods. Elbow venous blood $(5 \mathrm{ml})$ was extracted from an empty stomach in the morning into vacuum blood collection tubes without anticoagulant, centrifuged at $1,500 \mathrm{x}$ g and $4^{\circ} \mathrm{C}$ for $10 \mathrm{~min}$, and then stored in a low-temperature refrigerator at $-75^{\circ} \mathrm{C}$ for later use. The serum was then removed from the freezer and dissolved in a $4^{\circ} \mathrm{C}$ refrigerator before placing it at room temperature for complete dissolution. The serum expression levels of PAPP-A (cat. no. ab174314; Kemin Biotechnology Co., Ltd.), IL-8 [cat. no. Ant-111 (0.5 mg); Jingke Chemical Technology Co., Ltd.] and TNF- $\alpha$ (cat. no. BL-E1290h; Bdlisa Technology Co., Ltd.) were detected by enzyme-linked immunosorbent assay (ELISA) (19). The present study was carried out in strict accordance with the manufacturer's instructions. Firstly, sample, standard and blank wells were set up. Then, $50 \mu \mathrm{l}$ of the sample to be tested was added to the sample wells, $50 \mu 1$ of the standard was added to the standard wells, and blank wells contained no reagents. Subsequently, $100 \mu 1$ of horseradish peroxidase-labeled detection antibody (cat. no. P39810-100 mg; Acmec Biochemical Co., Ltd.) was added to the sample wells and standard wells, and then the plates were sealed and incubated at $37^{\circ} \mathrm{C}$ for $60 \mathrm{~min}$. Next, the liquid was discarded, the plates were patted dry and washed repeatedly 5 times and the substrates A and B (1:1) (included in the kit) were thoroughly mixed before their addition $(100 \mu \mathrm{l})$ to all the wells. The plates were then sealed and incubated at $37^{\circ} \mathrm{C}$ for $15 \mathrm{~min}$. Finally, $50 \mu \mathrm{l}$ termination solution was added to each well, and the absorbance [optical density (OD)] of each well at $450 \mathrm{~nm}$ was read by a fully-automatic enzyme label analyzer (M15; Chenlian Biotechnology Development Co., Ltd.) to calculate the expression levels of PAPP-A, IL-8 and TNF- $\alpha$.
Statistical analysis. Statistical analysis was performed using SPSS 19.0 (IBM Corp.), and the data was visualized by GraphPad Prism 6 (GraphPad Software, Inc.). The counting data were expressed as case/percentage $[\mathrm{n}(\%)]$ and the chi-square test was adopted for inter-group comparisons. The measurement data were expressed in the form of the mean $\pm \mathrm{SD}$, and the comparison of measurement data between the two groups was conducted by independent sample t-test. The area under the receiver operating characteristic (ROC) curve (AUC) was applied to evaluate the diagnostic value of peripheral blood PAPP-A in patients with EP. The correlation between PAPP-A and inflammatory factors IL-8 and TNF- $\alpha$ was assessed by Pearson correlation coefficient, and the independent risk factors affecting the incidence of EP were analyzed using Cox regression analysis. $\mathrm{P}<0.05$ was considered to indicate a statistically significant difference.

\section{Results}

General information. Seventy-five patients with EP admitted to our hospital were enrolled as the research group, and another 59 healthy pregnant women were enrolled as the control group. The participants in the research group were 21-35 years old, with an average age of $25.73 \pm 7.23$ years, while those in the control group were 20-35 years old, with an average age of $26.64 \pm 7.35$ years. No significant difference was observed in terms of age, gravidity, ethnicity, allergic reaction, smoking history, drinking history, diet, height, gestational age, abdominal circumference, systolic blood pressure, or diastolic blood pressure of patients in the two groups, while other baseline data represented by pre-pregnancy BMI, weight gain during pregnancy, and level of PAPP-A revealed statistically significant differences $(\mathrm{P}<0.05$; Table I).

Expression and diagnostic value of PAPP-A in the two groups. The expression levels of PAPP-A in the control group and the research group were $5.68 \pm 1.59 \mathrm{pg} / \mathrm{ml}$ and $4.94 \pm 1.36 \mathrm{pg} / \mathrm{ml}$, respectively, which indicated that PAPP-A in the control group was significantly higher than that in the research group $(\mathrm{P}<0.001)$. By further drawing the ROC curve, it was determined that the serum PAPP-A in the diagnosis of EP was 0.812 (95\% CI, 0.741-0.884), with an optimal cut-off value of 5.648, a sensitivity of 92.13, and a specificity of 78.33 (Fig. 1).

Changes of serum PAPP-A expression at different gestational weeks in the two groups. The corresponding serum PAPP-A expression levels at different gestational weeks in the control group and the research group were as follows: $\leq 6$ weeks: $15.16 \pm 15.27$ vs. $11.71 \pm 10.97 \mathrm{mU} / \mathrm{ml}$; $6-7$ weeks: $16.08 \pm 7.60$ vs. $15.12 \pm 9.30 \mathrm{mU} / \mathrm{ml} ; 7-8$ weeks: $19.37 \pm 10.23$ vs. $8.86 \pm 7.62 \mathrm{mU} / \mathrm{ml}$; 8-9 weeks: $18.52 \pm 16.92$ vs. $15.52 \pm 5.15 \mathrm{mU} / \mathrm{ml} ; \geq 9$ weeks: $22.33 \pm 14.64$ vs. $12.02 \pm 10.11 \mathrm{mU} / \mathrm{ml}$. From the aforementioned data, no significant difference in serum PAPP-A expression was observed between the two groups at weeks $\leq 6$, week 6-7, and week 8-9 ( $>>0.001)$, while the PAPP-A value of the control group at week $7-8$ and $\geq 9$ weeks was significantly higher than that of the research group ( $\mathrm{P}<0.001$; Table II and Fig. 2).

\section{Expression of inflammatory factors IL-8 and TNF- $\alpha$ in the two} groups. The expression levels of IL- 8 in the control group and the research group were $27.73 \pm 4.79 \mathrm{ng} / 1$ and $42.93 \pm 6.28 \mathrm{ng} / \mathrm{l}$, respectively, and the corresponding expression levels of 
Table I. Comparison of general data between two groups [n (\%)] (mean $\pm \mathrm{SD})$.

\begin{tabular}{|c|c|c|c|c|}
\hline Categories & Research group $(n=75)$ & Control group $(n=59)$ & $\mathrm{t} / \chi^{2}$ value & P-value \\
\hline Age (years) & $25.73 \pm 7.23$ & $26.64 \pm 7.35$ & 0.718 & 0.474 \\
\hline Gravidity (times) & $1.40 \pm 0.52$ & $1.50 \pm 0.62$ & 1.015 & 0.312 \\
\hline Ethnicity & & & 0.273 & 0.602 \\
\hline Han & $39(52.00)$ & $28(47.46)$ & & \\
\hline Ethnic minorities & $36(48.00)$ & $31(52.54)$ & & \\
\hline Allergic reaction & & & 0.970 & 0.325 \\
\hline Yes & $42(56.00)$ & $38(64.41)$ & & \\
\hline No & $33(44.00)$ & $21(35.59)$ & & \\
\hline Smoking & & & 0.158 & 0.691 \\
\hline Yes & $23(30.67)$ & $20(33.90)$ & & \\
\hline No & $52(69.33)$ & $39(66.10)$ & & \\
\hline Drinking & & & 0.001 & 0.980 \\
\hline Yes & $24(32.00)$ & $19(32.20)$ & & \\
\hline No & $51(68.00)$ & $40(67.80)$ & & \\
\hline Diet & & & 0.970 & 0.325 \\
\hline Dietary restriction & $33(44.00)$ & $21(35.59)$ & & \\
\hline None dietary restriction & $42(56.00)$ & $38(64.41)$ & & \\
\hline Height $(\mathrm{cm})$ & $161.54 \pm 5.23$ & $162.01 \pm 5.12$ & 0.521 & 0.603 \\
\hline Pre-pregnancy BMI $\left(\mathrm{kg} / \mathrm{m}^{2}\right)$ & & & 9.104 & 0.002 \\
\hline$\geq 23$ & $11(14.67)$ & $22(37.29)$ & & \\
\hline$<23$ & $64(85.33)$ & $37(62.71)$ & & \\
\hline Weight gain during pregnancy $(\mathrm{kg})$ & $13.52 \pm 4.26$ & $15.61 \pm 4.53$ & 2.742 & 0.007 \\
\hline Gestational age (weeks) & $23.95 \pm 1.85$ & $24.45 \pm 1.55$ & 1.666 & 0.098 \\
\hline Abdominal circumference $(\mathrm{cm})$ & $99.98 \pm 6.36$ & $101.87 \pm 6.65$ & 1.674 & 0.097 \\
\hline Systolic blood pressure (mmHg) & $114.12 \pm 9.06$ & $115.59 \pm 8.99$ & 0.936 & 0.351 \\
\hline Diastolic blood pressure (mmHg) & $72.98 \pm 7.16$ & $75.04 \pm 6.88$ & 1.682 & 0.095 \\
\hline PAPP-A (pg/ml) & $4.94 \pm 1.36$ & $5.68 \pm 1.59$ & 2.902 & 0.004 \\
\hline
\end{tabular}

PAPP-A, pregnancy-associated plasma protein-A.

Table II. Changes in the serum PAPP-A level at different gestational weeks in two groups [(mean $\pm \mathrm{sd}), \mathrm{mU} / \mathrm{ml}]$.

\begin{tabular}{lccccc}
\hline Groups & $\leq 6$ weeks & $6-7$ weeks & $7-8$ weeks & $8-9$ weeks & $\geq 9$ weeks \\
\hline Control group & $15.16 \pm 15.27$ & $16.08 \pm 7.60$ & $19.37 \pm 10.23$ & $18.52 \pm 16.92$ & $22.33 \pm 14.64$ \\
Research group & $11.71 \pm 10.97$ & $15.12 \pm 9.30$ & $8.86 \pm 7.62$ & $15.52 \pm 5.15$ & 1.454 \\
t & 1.521 & 0.742 & 6.815 & 0.148 & 4.814 \\
P-value & 0.131 & 0.459 & $<0.001$ & $<0.001$ \\
\hline
\end{tabular}

PAPP-A, pregnancy-associated plasma protein-A.

TNF- $\alpha$ in the control group and the research group were $20.83 \pm 4.37 \mathrm{ng} / \mathrm{l}$ and $29.37 \pm 4.38 \mathrm{ng} / \mathrm{l}$. The results revealed that the expression levels of inflammatory factors IL- 8 and TNF- $\alpha$ in the control group were significantly lower than those in the research group $(\mathrm{P}<0.001$; Fig. 3).

Correlation analysis between inflammatory factors $I L-8$, $T N F-\alpha$ and PAPP-A. Pearson correlation coefficients were applied to analyze the correlation of PAPP-A with IL-8 and TNF- $\alpha$. The results revealed that serum PAPP-A and IL- 8 were negatively correlated $(\mathrm{r}=-0.691 ; \mathrm{P}<0.001)$, and in addition, serum PAPP-A was negatively correlated with TNF- $\alpha$ $(r=-0.692 ; \mathrm{P}<0.001 ;$ Fig. 4).

Cox regression analysis of factors affecting the incidence of $E P$. Multivariate logistic regression analysis was carried out for 
Table III. Cox regression analysis assignment table.

\begin{tabular}{lcc}
\hline Factors & Variable & Assignment \\
\hline Age & $\mathrm{X} 1$ & No $=0$, yes $=1$ \\
Allergic reaction & $\mathrm{X} 2$ & No $=0$, yes $=1$ \\
Smoking history & $\mathrm{X} 3$ & No $=0$, yes $=1$ \\
Drinking history & $\mathrm{X} 4$ & No $=0$, yes $=1$ \\
Diet & $\mathrm{X} 5$ & No $=0$, yes $=1$ \\
History of genital surgery & $\mathrm{X} 6$ & No $=0$, yes $=1$ \\
History of salpingotomy & $\mathrm{X} 7$ & No $=0$, yes $=1$ \\
History of pelvic infection & $\mathrm{X} 8$ & No $=0$, yes $=1$ \\
History of lower abdominal surgery & $\mathrm{X} 9$ & No $=0$, yes $=1$ \\
History of ectopic pregnancy & $\mathrm{X} 10$ & No $=0$, yes $=1$ \\
PAPP-A & $\mathrm{X} 11$ & No $=0$, yes $=1$ \\
\end{tabular}

PAPP-A, pregnancy-associated plasma protein-A
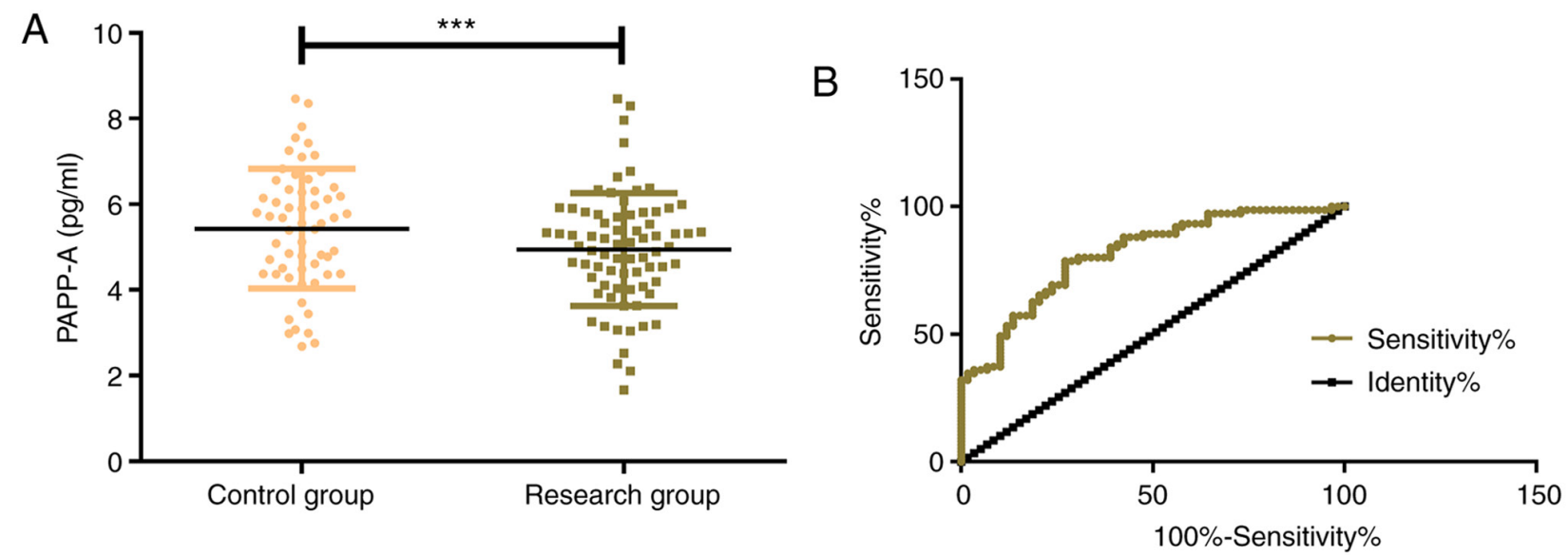

Figure 1. Expression and diagnostic value of PAPP-A. (A) The expression of PAPP-A in the research group was significantly lower than that in the control group. (B) ROC curve of PAPP-A in the diagnosis of ectopic pregnancy. ${ }^{* * *} \mathrm{P}<0.001$ vs. the control group. PAPP-A, pregnancy-associated plasma protein A; ROC, receiver operating characteristic.

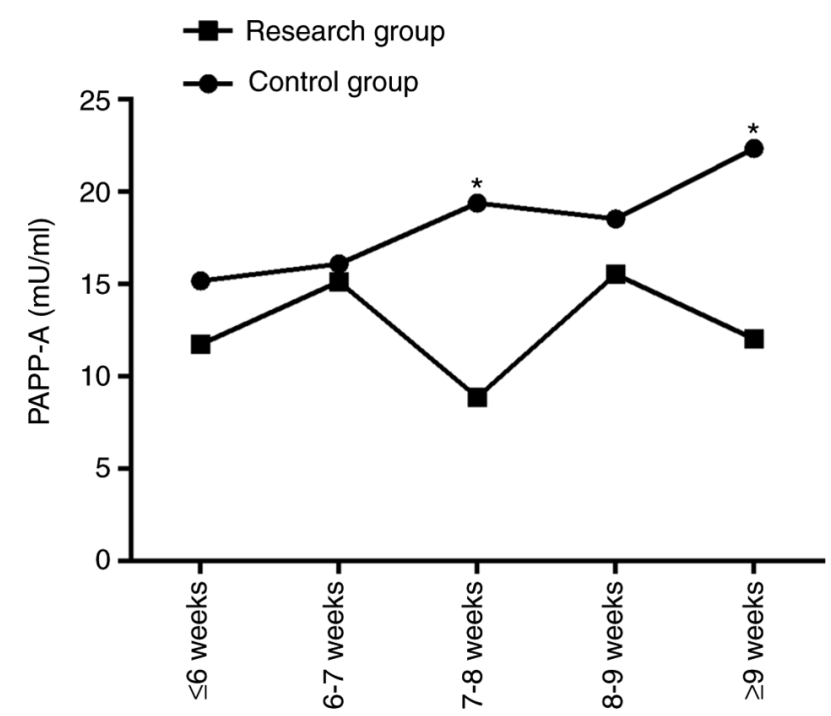

Figure 2. Changes of the serum PAPP-A expression at different gestational weeks in the two groups of patients (research and control groups). ${ }^{*} \mathrm{P}<0.05$ vs. the control group. PAPP-A, pregnancy-associated plasma protein-A. the factors with differences. The results indicated that a history of genital surgery $(\mathrm{P}=0.022)$, salpingotomy $(\mathrm{P}=0.005)$, pelvic infection $(\mathrm{P}=0.041), \mathrm{EP}(\mathrm{P}=0.013)$ and PAPP-A $(\mathrm{P}=0.003)$ were independent risk factors affecting the incidence of EP. Among the risk factors aforementioned above, history of salpingotomy, EP and low PAPP-A expression increased the risk of EP (Tables III and IV).

\section{Discussion}

Worldwide, gestational placenta related-diseases are one of the leading causes of maternal and neonatal morbidity and mortality (20). Of these, EP is a pregnancy implanted outside the endometrium, which hazards the health of patients and is a major cause of sudden death in women of childbearing age (21). In addition, these women often suffer from complications, such as organ rupture with massive bleeding, treatment-related risks, recurrent EP and infertility risk (22). Therefore, the diagnosis of EP is of vital significance for reducing the morbidity and mortality associated with this disease (23). 

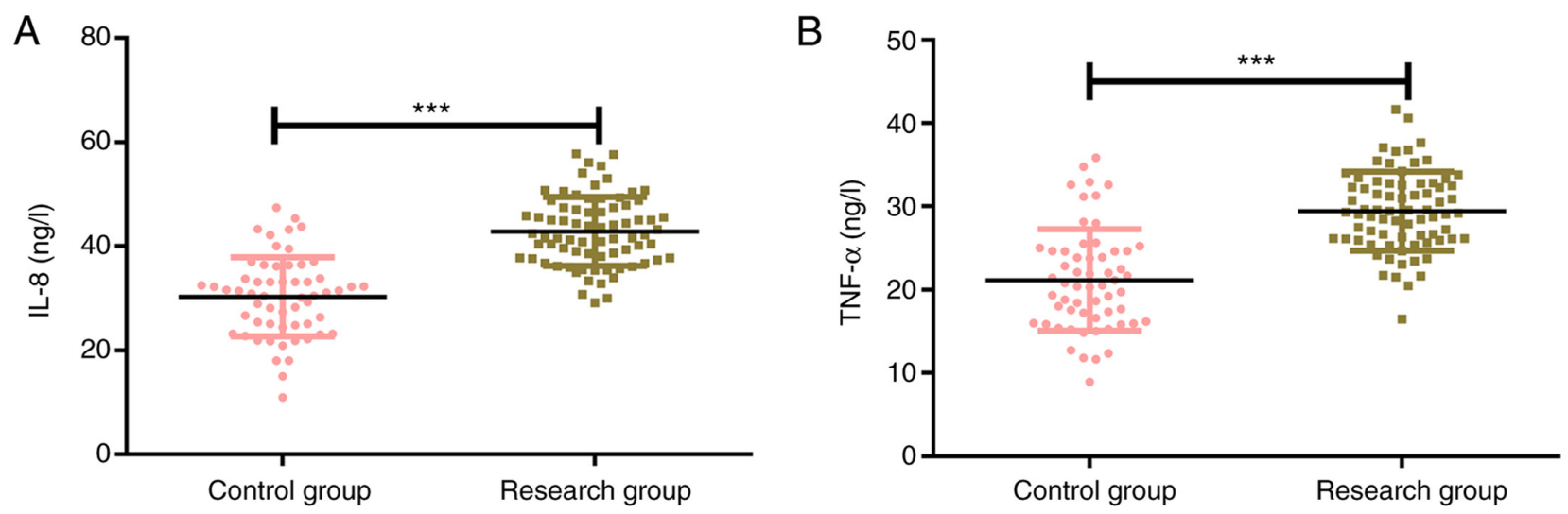

Figure 3. Expression levels of markers IL-8 and TNF- $\alpha$. (A) The expression of IL-8 in the research group was significantly higher than that in the control group. (B) The expression of TNF- $\alpha$ in the research group was significantly higher than that in the control group. ${ }^{* * *} \mathrm{P}<0.001$ vs. the control group. IL-8, interleukin-8; TNF- $\alpha$, tumor necrosis factor- $\alpha$.
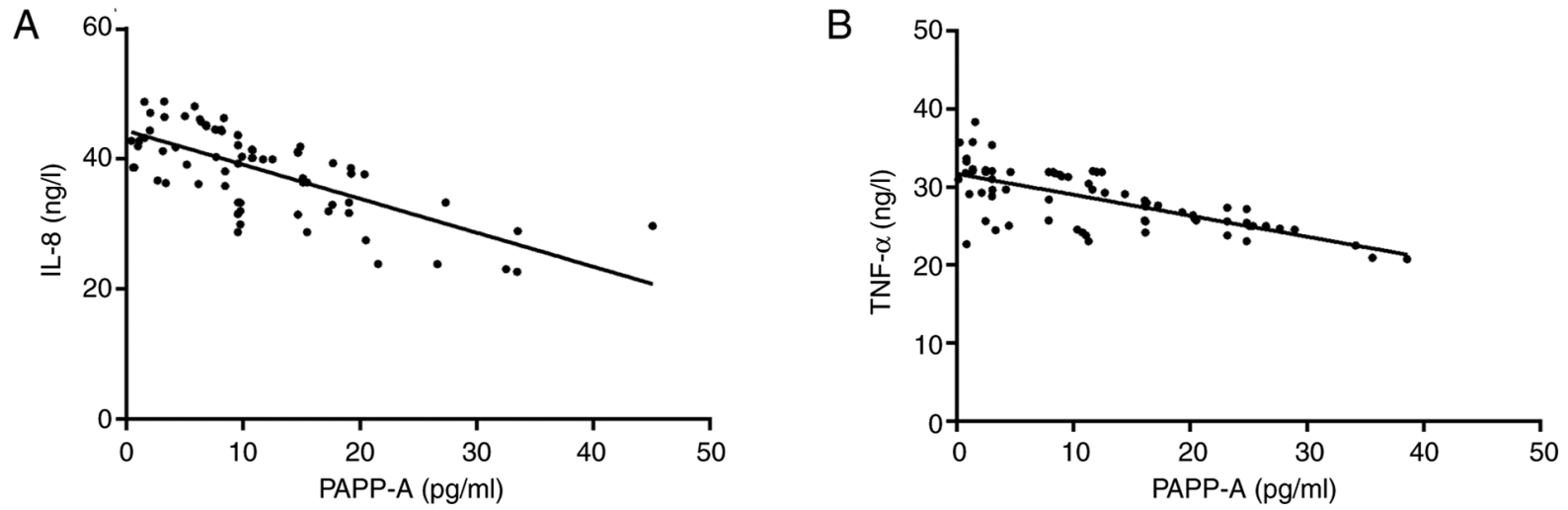

Figure 4. Correlation analysis between inflammatory factors IL-8, TNF- $\alpha$ and PAPP-A. (A) PAPP-A was negatively correlated with marker IL-8 (r=-0.691; $\mathrm{P}<0.001)$. (B) PAPP-A was negatively correlated with marker TNF- $\alpha(\mathrm{r}=-0.692 ; \mathrm{P}<0.001)$. IL-8, interleukin- 8 ; TNF- $\alpha$, tumor necrosis factor- $\alpha$; PAPP-A, pregnancy-associated plasma protein-A.

PAPP-A, a placental-derived glycoprotein produced by trophoblast cells that gradually increases during the first few weeks of a viable pregnancy, has been revealed to be diagnostic in a variety of abnormal obstetric conditions (24). The present study firstly detected the expression of PAPP-A in EP. It was observed that the serum PAPP-A expression was significantly lower in EP patients in the research group than that of patients in the control group, and the AUC of patients diagnosed with EP by PAPP-A was 0.812 , with a sensitivity of 92.13 and a specificity of 78.33 , indicating that PAPP-A may be a potential diagnostic and therapeutic target for EP. PAPP-A expression was further analyzed in the two groups at different gestational weeks, and different PAPP-A levels were observed, that is, the control group presented a stable increasing trend of PAPP-A at each gestational week, while the research group exhibited an irregular but insignificant increase. At 7-8 weeks and $\geq 9$ weeks, the PAPP-A value in the control group was significantly higher than that in the research group, which was probably due to the fact that the PAPP-A value between the two groups gradually increased with the prolonging of amenorrhea. Therefore, according to the detection of low expression of PAPP-A in the serum of EP patients, it was theorized that the determination of PAPP-A in serum could be used as a routine measurement for pregnant patients. In a study of Kaijomaa et al on adverse pregnancy (25), PAPP-A was underexpressed in patients with adverse pregnancy, indicating that PAPP-A was of certain diagnostic value and was an important risk factor for EP, which was consistent with the results of the present study.

IL-8 is a chemokine that has been clinically demonstrated to play a major role in tumor immune escape by promoting an immunosuppressive tumor microenvironment, and it has been revealed that high levels of IL-8 are associated with poor prognosis in a variety of tumors (26). According to previous studies, serum IL-8 was revealed to be significantly higher in EP women than in women with normal pregnancy in utero, and the diagnosis and identification of EP women with chlamydia trachomatis infection was related to the level of IL-8 $(27,28)$. TNF- $\alpha$ is an inflammatory cytokine secreted by macrophages and monocytes, which exerts a marked effect on inflammatory response, cell apoptosis and proliferation (29). There is also research showing that TNF- $\alpha$ has attracted the attention of clinicians and scholars due to its involvement in the development of inflammatory response, autoimmunity, neoplastic disease and the endocrine system (30). For example, TNF- $\alpha$ induces the apoptosis of cytotrophoblast cells, which also suggests that abnormal 
Table IV. Univariate and multivariate Cox regression analysis of ectopic pregnancy.

\begin{tabular}{|c|c|c|c|c|}
\hline \multirow[b]{2}{*}{ Factors } & \multicolumn{2}{|c|}{ Univariate } & \multicolumn{2}{|c|}{ Multivariate } \\
\hline & $\mathrm{HR}(95 \mathrm{CI} \%)$ & P-value & $\mathrm{HR}(95 \mathrm{CI} \%)$ & P-value \\
\hline Age & $1.549(0.519-4.628)$ & 0.438 & & \\
\hline Allergic reaction & $0.553(0.157-2.042)$ & 0.372 & & \\
\hline Smoking history & $1.008(0.991-1.022)$ & 0.368 & & \\
\hline Drinking history & $0.564(0.201-1.580)$ & 0.276 & & \\
\hline Diet & $2.748(0.705-10.701)$ & 0.143 & & \\
\hline History of genital surgery & $1.406(1.092-1.812)$ & 0.043 & $1.138(0.857-1.514)$ & 0.022 \\
\hline History of salpingotomy & $6.459(1.408-29.575)$ & 0.017 & $12.852(2.297-71.238)$ & 0.005 \\
\hline History of pelvic infection & $6.108(1.385-24.954)$ & 0.018 & $2.601(1.032-6.538)$ & 0.041 \\
\hline History of lower abdominal surgery & $2.270(0.901-1.792)$ & 0.175 & - & - \\
\hline History of ectopic pregnancy & $0.292(0.124-0.689)$ & 0.005 & $0.357(0.158-0.735)$ & 0.013 \\
\hline PAPP-A & $8.356(2.128-3.846)$ & 0.002 & $5.817(2.157-15.756)$ & 0.003 \\
\hline
\end{tabular}

PAPP-A, pregnancy-associated plasma protein-A.

expression of TNF- $\alpha$ may adversely affect the development and function of the placenta (31). Growing evidence reveals that TNF- $\alpha$ mediates pregnancy complications and increases the sensitivity of infertility, while increased TNF- $\alpha$ in the placenta increases the abortion rate (32). Soriano et al (33) revealed that the expression of serum inflammatory factors IL-6, IL-8 and TNF- $\alpha$ in EP women was significantly higher than that in normal pregnant women, suggesting that the overexpression of these three inflammatory mediators stimulated the inflammatory cascade in patients and aggravated the progression of EP. Furthermore, other researchers have reported that the pro-inflammatory factors TNF- $\alpha$, IL- $1 \beta$ and IL- 6 stimulate the expression of PAPP-A in cultured cells (34). In the present study, the detection of inflammatory factors demonstrated that the expression levels of inflammatory factors IL- 8 and TNF- $\alpha$ in the research group were significantly higher than those in the control group, while PAPP-A was negatively correlated with the two, suggesting that the low expression of PAPP-A in an inflammatory environment may be related to the occurrence and development of EP. Concerning the risk factors of EP, Zhang et al (35) revealed that a history of $\mathrm{EP}$, infertility, and salpingotomy were all risk factors. In the present study, Cox regression analysis revealed that a history of genital surgery, salpingotomy, pelvic infection, EP and low expression of PAPP-A were the risk factors of EP, among which a history of salpingotomy, EP and low expression of PAPP-A increased the risks. Therefore, PAPP-A is anticipated to be a biomarker for the diagnosis and prognosis of EP.

The present study strictly screened the participants according to the inclusion and exclusion criteria and ensured the rigor and reliability of the research. Although in the present study it was confirmed that PAPP-A is lowly expressed in EP patients and is negatively correlated with inflammatory factors IL- 8 and TNF- $\alpha$, there are still some certain limitations in this study. We will perform more basic experiments in the future, investigating the specific regulatory mechanism of PAPP-A on EP, thus further verifying that PAPP-A can be a potential therapeutic target for EP.

In conclusion, PAPP-A was downregulated in patients with $\mathrm{EP}$ and may be a useful marker for the diagnosis and prognosis assessment of this condition.

\section{Acknowledgements}

Not applicable.

\section{Funding}

No funding was received.

\section{Availability of data and materials}

The datasets used and/or analyzed during the present study are available from the corresponding author on reasonable request.

\section{Authors' contributions}

$\mathrm{XZ}$ and CW conceived and designed the study, collected, analyzed and interpreted the experimental data, drafted this paper, and revised the manuscript critically for important intellectual content. Both authors read and approved the final manuscript.

\section{Ethics approval and consent to participate}

The study was approved by the Ethics Committee of the Affiliated Hospital of Jining Medical University (Jining, China). Signed written informed consents were obtained from the patients and/or guardians.

\section{Patient consent for publication}

Not applicable. 


\section{Competing interests}

The authors declare that they have no competing interests.

\section{References}

1. Perkins KM, Boulet SL, Kissin DM and Jamieson DJ: National ART Surveillance (NASS) Group. Risk of ectopic pregnancy associated with assisted reproductive technology in the United States, 2001-2011. Obstet Gynecol 125: 70-78, 2015.

2. Bronson R: Ectopic pregnancy-still a challenge. Fertil Steril 110: 1265-1266, 2018

3. Refaat B, Dalton E and Ledger WL: Ectopic pregnancy secondary to in vitro fertilisation-embryo transfer: Pathogenic mechanisms and management strategies. Reprod Biol Endocrinol 13: 30, 2015

4. Ashshi AM, Batwa SA, Kutbi SY, Malibary FA, Batwa M and Refaat B: Prevalence of 7 sexually transmitted organisms by multiplex real-time PCR in Fallopian tube specimens collected from Saudi women with and without ectopic pregnancy. BMC Infect Dis 15: 569, 2015.

5. Li C, Zhao WH, Zhu Q, Cao SJ, Ping H, Xi X, Qin GJ, Yan MX, Zhang D, Qiu J and Zhang J: Risk factors for ectopic pregnancy: A multi-center case-control study. BMC Pregnancy Childbirth 15: 187,2015

6. Lagana AS, Vitale SG, De Dominici R, Padula F, Rapisarda AM Biondi A, Cianci S, Valenti G, Capriglione S, Frangez HB and Sturlese E: Fertility outcome after laparoscopic salpingostomy or salpingectomy for tubal ectopic pregnancy A 12-years retrospective cohort study. Ann Ital Chir 87: 461-465, 2016.

7. Hsu JY, Chen L, Gumer AR, Tergas AI, Hou JY, Burke WM, Ananth CV, Hershman DL and Wright JD: Disparities in the management of ectopic pregnancy. Am J Obstet Gynecol 217: 49.e1-49.e10, 2017.

8. Chanana C, Gupta N, Bansal I, Hooda K, Sharma P, Gupta M, Gandhi D and Kumar Y: Different sonographic faces of ectopic pregnancy. J Clin Imaging Sci 7: 6, 2017.

9. Bøtkjær JA, Noer PR, Oxvig C and Yding Andersen C: A common variant of the pregnancy-associated plasma protein-A (PAPPA) gene encodes a protein with reduced proteolytic activity towards IGF-binding proteins. Sci Rep 9: 13231, 2019.

10. Bale LK, Chakraborty S and Conover CA: Inducible reduction in pregnancy-associated plasma protein-A gene expression inhibits established atherosclerotic plaque progression in mice. Endocrinology 155: 1184-1187, 2014.

11. Smith YE, Toomey S, Napoletano S, Kirwan G, Schadow C, Chubb AJ, Mikkelsen JH, Oxvig C and Harmey JH: Recombinant PAPP-A resistant insulin-like growth factor binding protein 4 (dBP4) inhibits angiogenesis and metastasis in a murine model of breast cancer. BMC Cancer 18: 1016, 2018

12. Prithviraj P, Anaka M, McKeown SJ, Permezel M, Walkiewicz M, Cebon J, Behren A and Jayachandran A: Pregnancy associated plasma protein-A links pregnancy and melanoma progression by promoting cellular migration and invasion. Oncotarget 6 : 15953-15965, 2015.

13. Sert A, Leung K, Waring ME, Rojas-Rodriguez R, Corvera S and Moore Simas TA: Association between first trimester pregnancy associated plasma protein-A (PAPP-A) and gestational diabetes mellitus development. 2016.

14. Peeva G, Oakley L, Von Rège I, Nicolaides K and Oteng-Ntim E: Does first trimester serum pregnancy-associated plasma protein A differ in pregnant women with sickle cell disease? Prenat Diagn 39: 921-924, 2019.

15. Antsaklis P, Fasoulakis Z, Theodora M, Diakosavvas M and Kontomanolis EN: Association of low maternal pregnancy-associated plasma protein A with adverse perinatal outcome Cureus 11: e4912, 2019

16. Papastefanou I, Wright D, Syngelaki A, Lolos M, Anampousi K and Nicolaides KH: Competing-risks model for prediction of small-for-gestational-age neonate from maternal characteristics and serum pregnancy-associated plasma protein-A at 11-13 weeks gestation. Ultrasound Obstet Gynecol 56: 541-548, 2020.
17. Xin H, Liu W and Li P: Diagnostic value of detection of serum $\beta$-HCG and CT-IgG combined with transvaginal ultrasonography in early tubal pregnancy. Exp Ther Med 16: 277-281, 2018.

18. Hoffmann S, Abele H and Bachmann C: Spontaneous bilateral tubal ectopic pregnancy: Incidental finding during laparoscopy-brief report and review of literature. Geburtshilfe Frauenheilkd 76 413-416, 2016.

19. Hornbeck PV: Enzyme-linked immunosorbent assays. Curr Protoc Immunol 110: 2.1.1-2.1.23, 2015

20. Browne JL, Klipstein-Grobusch K, Koster MP, Ramamoorthy D, Antwi E, Belmouden I, Franx A, Grobbee DE and Schielen PC: Pregnancy associated plasma protein-a and placental growth factor in a sub-Saharan African population: A nested cross-sectional study. PLoS One 11: e0159592, 2016.

21. Sowter M: Finding an ectopic pregnancy. Imaging 17, 2015.

22. Perlman BE, Guerrero K, Karsalia R and Heller DS: Reproductive outcomes following a ruptured ectopic pregnancy. Eur J Contracept Reprod Health Care 25: 206-208, 2020.

23. Murano T, Shaker L and Marco CA: Evaluation and management of ectopic pregnancy in the emergency department. Emergency Med Rep 40, 2019.

24. Batson RJ, Mills BB, Nagy Z and Roudebush W: Pregnancyassociated plasma protein A (PAPP-A): A biomarker for the aid in risk stratification of nonviable pregnancy. Fertil Steril 104 e351, 2015.

25. Kaijomaa M, Rahkonen L, Ulander VM, Hämäläinen E, Alfthan H, Markkanen H, Heinonen S and Stefanovic V: Low maternal pregnancy-associated plasma protein A during the first trimester of pregnancy and pregnancy outcomes. Int J Gynaecol Obstet 136: 76-82, 2017

26. Melero Bermejo I, Jaffee EM, Davar D, Cardarelli J, Williams D, Phillips P, Phillips P, Carleton M, Zhou M, De Henau O, et al: Phase $1 \mathrm{~b} / 2$ study of nivolumab in combination with an anti-IL-8 monoclonal antibody, BMS-986253, in a biomarker-enriched population of patients with advanced cancer. J Clin Oncol 36 (Suppl 15): TPS3109, 2018.

27. Shao R, Feng Y, Zou S, Li X, Cui P and Billig H: Quantitative analysis of hormones and inflammatory cytokines in Chlamydia trachomatis-infected women with tubal ectopic pregnancy and early intrauterine pregnancy. Data Brief 6: 135-142, 2015

28. Ma L, Li Z, Xi S, Guo Q, Zhao P, Li W, Ai J and Chen X: Tubal ectopic pregnancy occurrence is associated with high expressions of prokineticin receptors and aberrant secretion of inflammatory cytokines. Am J Transl Res 12: 5741-5751, 2020.

29. Jiang PR, Cao Z, Qiu ZL, Pan JW, Zhang N and Wu YF: Plasma levels of TNF- $\alpha$ and MMP-9 in patients with silicosis. Eur Rev Med Pharmacol Sci 19: 1716-1720, 2015.

30. Zaka M, Abbasi BH and Durdagi S: Novel tumor necrosis factor- $\alpha$ (TNF- $\alpha)$ inhibitors from small molecule library screening for their therapeutic activity profiles against rheumatoid arthritis using target-driven approaches and binary QSAR models. J Biomol Struct Dyn 37: 2464-2476, 2019.

31. Cha HH, Hwang JR, Kim HY, Choi SJ, Oh SY and Roh CR: Autophagy induced by tumor necrosis factor $\alpha$ mediates intrinsic apoptosis in trophoblastic cells. Reprod Sci 21: 612-622, 2014.

32. Li HH, Xu XH, Tong J, Zhang KY, Zhang C and Chen ZJ: Association of TNF- $\alpha$ genetic polymorphisms with recurrent pregnancy loss risk: A systematic review and meta-analysis. Reprod Biol Endocrinol 14: 6, 2016.

33. Soriano D, Hugol D, Quang NT and Darai E: Serum concentrations of interleukin-2R (IL-2R), IL-6, IL-8, and tumor necrosis factor alpha in patients with ectopic pregnancy. Fertil Steril 79: 975-980, 2003

34. Tang SL, Zhao ZW, Liu SM, Wang G, Yu XH, Zou J, Wang SQ, Dai XY, Fu MG, Zheng XL, et al: Pregnancy-associated plasma protein-A accelerates atherosclerosis by regulating reverse cholesterol transport and inflammation. Circ J 83: 515-523, 2019.

35. Zhang D, Shi W, Li C, Yuan JJ, Xia W, Xue RH, Sun J and Zhang J: Risk factors for recurrent ectopic pregnancy: A case-control study. BJOG 123 (Suppl 3): S82-S89, 2016.

This work is licensed under a Creative Commons Attribution-NonCommercial-NoDerivatives 4.0 International (CC BY-NC-ND 4.0) License. 